\title{
Effect of Deposition Rate on the Property of ZnO Thin Films Deposited by Pulsed Laser Deposition
}

\author{
Jae-Won Kim*, Hong-Seong Kang* and Sang-Yeol Lee ${ }^{\dagger}$
}

\begin{abstract}
ZnO}$ thin films were deposited at different repetition rates of $5 \mathrm{~Hz}$ and $10 \mathrm{~Hz}$ by pulsed laser deposition. X-ray diffraction (XRD) full widths at half maximum (FWHMs) of (002) ZnO peak in $\mathrm{ZnO}$ thin film deposited at $5 \mathrm{~Hz}$ and $10 \mathrm{~Hz}$ was 0.22 and $0.26^{\circ}$, respectively. The grain size of $\mathrm{ZnO}$ thin film deposited at $5 \mathrm{~Hz}$ was larger than that of $10 \mathrm{~Hz}$. The variation of repetition rates did not have an effect on the optical property of $\mathrm{ZnO}$ thin films. The degradation of the crystalline quality and surface morphology in $\mathrm{ZnO}$ thin film deposited at $10 \mathrm{~Hz}$ resulted from supersaturation effect by decrease of time interval between a $\mathrm{ZnO}$ particle arriving on a substrate by laser shot and a $\mathrm{ZnO}$ particle arriving on a substrate by next laser shot.
\end{abstract}

Keywords: pulsed laser deposition, repetition rate, $\mathrm{ZnO}$ thin film.

\section{Introduction}

$\mathrm{ZnO}$ is a wide-bandgap $\Pi-\mathrm{VI}$ semiconductor that has a hexagonal wurtzite structure [1]. $\mathrm{ZnO}$ thin film has been investigated for various applications such as a transparent conductive contact, thin-film gas sensor, varistor, solar cell, luminescent material, surface electro-acoustic wave device, light emitting device, and others due to good electric, piezoelectric and optical properties [2-4]. Particularly, $\mathrm{ZnO}$-based light emitting diodes (LEDs) and laser diodes (LDs) have been studied intensively since several eptaxial methods have produced excellent material and the production of p-type $\mathrm{ZnO}$ has been achieved [5-7].

$\mathrm{ZnO}$ thin film has been deposited by various deposition techniques such as laser molecular beam epitaxy (L-MBE), metalorganic vapor-phase epitaxy (MOVPE), rf magnetron sputtering, sol-gel deposition and pulsed laser deposition (PLD). Especially, the PLD has advantages of being able to employ a relatively high oxygen partial pressure and also to achieve high-quality crystalline films with relatively high deposition rate at low temperatures because the high energy $(\sim 100 \mathrm{eV})$ of the ablated particles can be obtained in the laser produced plume [8].

In this study, $\mathrm{ZnO}$ thin films were grown at different repetition rates without changing other experimental parameters, such as energy density of the laser, ambient gas pressure and the distance between a target and a substrate. The properties of $\mathrm{ZnO}$ thin films were systematically

$\dagger$ Corresponding Author: Dept. of Electrical and Electronic Engineering, Yonsei Univerity, Korea.(sylee@yonsei.ac.kr)

* Dept. of Electrical and Electronic Engineering, Yonsei Univerity, Korea.

Received October 12, 2005 ; Accepted December 19, 2005 investigated as a function of repetition rate.

\section{Experiment}

$\mathrm{ZnO}$ thin films were deposited on (001) sapphire substrates at different repetition rates by a pulsed laser deposition. Two different repetition rates were used; $5 \mathrm{~Hz}$, 10Hz. The pulsed Nd:YAG laser was operated at a wavelength of $355 \mathrm{~nm}$. The energy density was $2.5 \mathrm{~J} / \mathrm{cm}^{2}$ and the focused laser beam illuminated on a rotating $\mathrm{ZnO}$ target at $33.7^{\circ}$ incident angle. The deposition chamber was initially evacuated to the pressure in the range from $10^{-6}$ to $10^{-7}$ Torr by a turbomolecular pump, and finally filled with $99.99 \%$ pure oxygen of $350 \mathrm{mT}$ Torr. The target was a 99.999\% pure ceramic $\mathrm{ZnO}$ target, and the distance between the target and the center of the substrate was $50 \mathrm{~mm}$.

The schematic diagram of the PLD system used in this study is shown in Fig. 1. The substrate temperature was

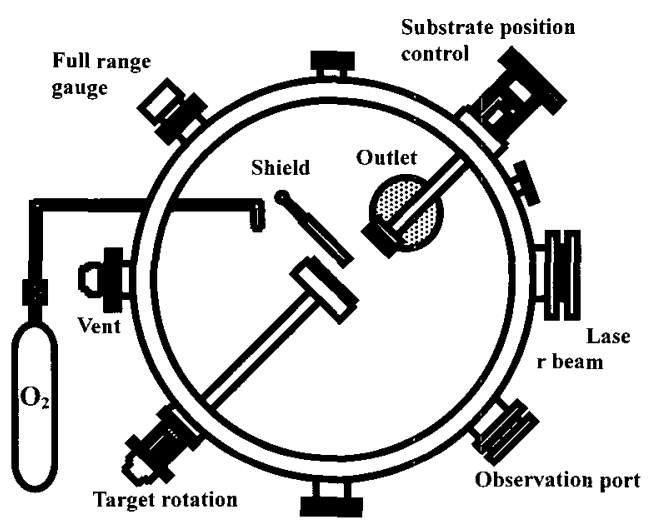

Fig. 1 Schematic diagram of PLD system (top view). 
$400^{\circ} \mathrm{C}$ because $\mathrm{ZnO}$ thin film fabricated at $400^{\circ} \mathrm{C}$ exhibited good optical and structural properties $[8,12,15]$. The film thickness of $\mathrm{ZnO}$ thin films measured by cross sectional scanning electron microscopy (SEM) images was about $10,000 \AA$. The crystal quality was investigated by XRD with a Ni-filtered $\mathrm{CuK} \alpha\left(\lambda=1.5418 \times 10^{-10} \mathrm{~m}\right)$ source. The surface morphology was observed by scanning electron microscopy (SEM). The optical properties of $\mathrm{ZnO}$ thin films were characterized by PL with a HeCd laser as a light source using the excitation wavelength of $325 \mathrm{~nm}$ and the power of $20 \mathrm{~mW}$. All measurements were performed at room temperature.

\section{Results and Discussion}

Fig. 2 shows XRD spectra of $\mathrm{ZnO}$ thin films deposited at $5 \mathrm{~Hz}$ and $10 \mathrm{~Hz}$. All $\mathrm{ZnO}$ films were found to be well caxis oriented exhibiting dominant (002) and minor (101) and (100) peaks. The full width at half maximum (FWHM) of $(002) \mathrm{ZnO}$ peak deposited at $5 \mathrm{~Hz}$ was $0.22^{\circ}$ as indicated in Fig. 2 (a), which was smaller than that of $(002)$ $\mathrm{ZnO}$ peak deposited at $10 \mathrm{~Hz}$ of $0.26^{\circ}$ as presented in Fig. 2 (b). This means that the grain size of $\mathrm{ZnO}$ fabricated at 5 $\mathrm{Hz}$ is larger than that fabricated at $10 \mathrm{~Hz}$ and the film quality of $\mathrm{ZnO}$ deposited at $5 \mathrm{~Hz}$ is better than that deposited at $10 \mathrm{~Hz}$.

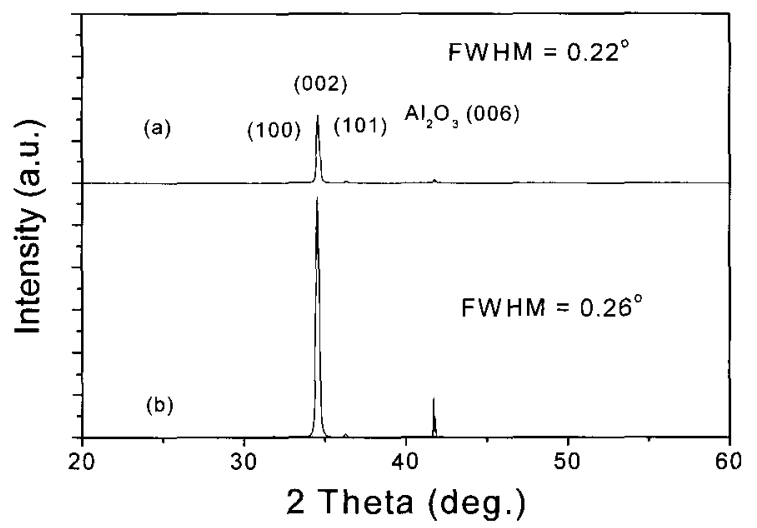

Fig. 2 XRD spectra of $\mathrm{ZnO}$ thin films deposited at (a) $5 \mathrm{~Hz}$ and (b) $10 \mathrm{~Hz}$.

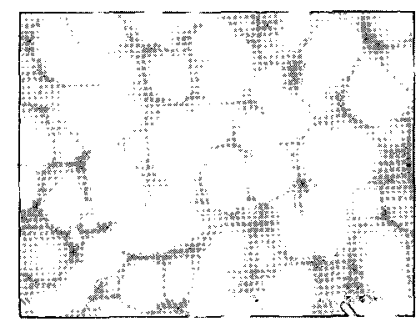

(a)

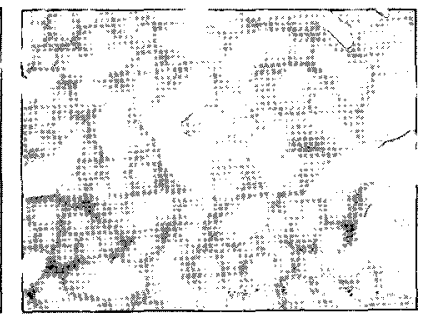

(b)
Fig. 3 Surface SEM images of $\mathrm{ZnO}$ thin films deposited at (a) $5 \mathrm{~Hz}$ and (b) $10 \mathrm{~Hz}$.
Fig. 3 shows surface SEM images of $\mathrm{ZnO}$ thin films deposited at different repetition rates. According to Scherrer's formula, the increase of grain size in film means the decrease of FWHM of XRD spectra [9]. Similarly, the grain size of $\mathrm{ZnO}$ thin film deposited at $5 \mathrm{~Hz}$, having smaller XRD FWHM value as exhibited in Fig. 2, was larger than that of $\mathrm{ZnO}$ thin film deposited at $10 \mathrm{~Hz}$. The $\mathrm{XRD}$ result as displayed in Fig. 2 was consistent with the SEM result as displayed in Fig. 3.

Fig. 4 (a) presents the PL spectra of $\mathrm{ZnO}$ thin films deposited at $5 \mathrm{~Hz}$ and $10 \mathrm{~Hz}$. UV emission of $380 \mathrm{~nm}$ and broad visible emission near $500 \mathrm{~nm}$ were observed in all thin films. The intensity of $\mathrm{UV}$ emission of $\mathrm{ZnO}$ thin film is dependent on the microcrystalline structure and stoichiometry and the visible emission is mainly due to defects, such as oxygen vacancies and zinc interstitials [1012]. Therefore, UV emission intensity/visible emission intensity ratio could be the key factor required to estimate the optical property of $\mathrm{ZnO}$ thin film. However, UV emission intensity/visible emission intensity ratios of $\mathrm{ZnO}$ thin films deposited at $5 \mathrm{~Hz}$ and $10 \mathrm{~Hz}$ were almost identical, being 4.543 and 4.58 , respectively. In other words, the variation of repetition rates did not have an effect on the optical property of $\mathrm{ZnO}$ thin film.

Although the variation of repetition rates could not have an effect on the optical property of $\mathrm{ZnO}$ thin film, the crystalline quality and surface morphology of $\mathrm{ZnO}$ thin film deposited at $10 \mathrm{~Hz}$ were inferior to that of $\mathrm{ZnO}$ thin film deposited at $5 \mathrm{~Hz}$ as shown in the XRD and SEM results in Fig. 2 and Fig. 3. It is well known that films are often grown at high supersaturation, that is, the flux of the impinging particle is so high, and the substrate temperature is so low, that incoming particles cannot form the high quality thin film when they land on the surface $[13,14]$. The time interval between a $\mathrm{ZnO}$ particle arriving on a substrate by laser shot and a $\mathrm{ZnO}$ particle arriving on a substrate by next laser shot decreased as repetition rate

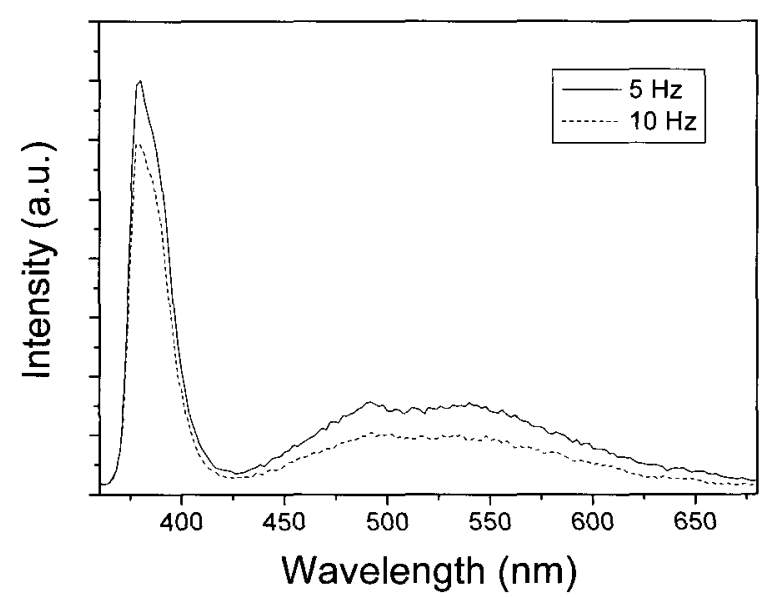

Fig. $4 \mathrm{PL}$ spectra of $\mathrm{ZnO}$ thin films deposited at $5 \mathrm{~Hz}$ and $10 \mathrm{~Hz}$. 
increased. The decline of time interval between a laser shot and next laser shot gives rise to the supersaturation effect and results in the degradation of the film quality.

In this study, $\mathrm{ZnO}$ thin films were deposited at different repetition rates of $5 \mathrm{~Hz}$ and $10 \mathrm{~Hz}$ by pulsed laser deposition. The amount of ablated species arriving on a substrate per laser shot increased as repetition rate increased. The rise in the amount of ablated species arriving on a substrate per laser shot caused supersaturation effect and resulted in deterioration of film quality.

\section{Conclusion}

$\mathrm{ZnO}$ thin films were deposited at repetition rates of $5 \mathrm{~Hz}$ and $10 \mathrm{~Hz}$. XRD FWHM of (002) $\mathrm{ZnO}$ peak in $\mathrm{ZnO}$ thin film deposited at $5 \mathrm{~Hz}$ was smaller than that of $10 \mathrm{~Hz}$. The grain size of $\mathrm{ZnO}$ thin film deposited at $5 \mathrm{~Hz}$ was larger that that of $10 \mathrm{~Hz}$. The optical property of $\mathrm{ZnO}$ thin films depending on repetition rate was nearly equivalent. The degradation of the crystalline quality and surface morphology in $\mathrm{ZnO}$ thin film deposited at $10 \mathrm{~Hz}$ resulted from supersaturation effect by decrease of time interval between a $\mathrm{ZnO}$ particle arriving on a substrate by laser shot and a $\mathrm{ZnO}$ particle arriving on a substrate by next laser shot.

\section{Acknowledgements}

This work was supported by grant No.R01-2004-00010195-0 (2005) from the Basic Research Program of the Korea Science \& Engineering Foundation.

\section{References}

[1] S. King, J.G.E. Gardeniers, and I.W. Boyd, Appl. Surface Sci. 96-98 (1996) 811.

[2] W. W. Wenas, A. Yamada, and K. Takahashi, J. Appl. Phys. 70 (1991) 7119.

[3] H. Ohta, K. Kawamura, M. Orita, M. Hirano, N. Sarukura, and H. Hosono, Appl. Phys. Lett. 77 (2000) 475.

[4] S. A. Studenikin, Michael Cocivera, W. Kellner and H. Pascher, Journal of Luminescence 91 (2000) 223.

[5] A. Ohtomo, K. Tamura, K. Saikusa, K. Takahashi, T. Makino, Y. Segawa, H. Koinuma, and M. Kawasaki, Appl. Phys. Lett. 75 (2003) 2635.

[6] Sang Yeol Lee, Eun Sub Shim, Hong Seong Kang, Seong Sik Pang, and Jeong Seok Kang, Thin Solid Films, 473 (2005) 31.

[7] Kyoung Kook Kim, Hyun Sik Kim, Dae Kue Hwang,
Jae Hong Lim, and Seong Ju Park, Applied Physics Letters, 83 (2003) 63.

[8] Jeong Seok Kang, Hong Seong Kang, Seong Sik Pang, Eun Sub Shim, and Sang Yeol Lee, Thin Solid Films, 443 (2003) 5.

[9] B.D.Cullity, S.R.Stock, Elements of X-ray Diffraction $3^{\text {rd }}$ Edition, Prentice Hall, 2001, p. 170.

[10] Z.K. Tang, Q.K.L. Wong, P. Yu, Appl. Phys. Lett. 72 (1998) 3270.

[11] B.J. Jin, S.H. Bae, S.Y. Lee, and S. Im, Materials Science and Engineering B71 (2000) 301.

[12] Hong Seong Kang, Jeong Seok Kang, Jae Won Kim, and Sang Yeol Lee, J. Appl. Phys 95 (2004) 1246.

[13] Janos H. Fendler and Imre Dékány, Nanoparticles in Solids and Solutions, NATO ASI Series, (1996).

[14] Deuk-Kyu Hwang, Kyu-Hyun Bang, Min-Chang Jeong, and Jae-Min Myoung, J. Cryst. Growth 254 (2003) 449.

[15] Sang Hyuck Bae, Sang Yeol Lee, Beom Jun Jin, and Seongil Im, Applied Surface Science 169-170 (2001) 525 .

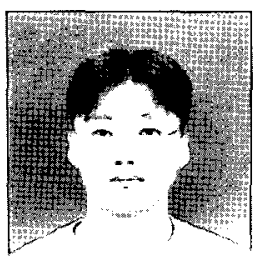

\section{Jae-Won Kim}

He received B.S. and M.S. degree in Electrical and Electronic Engineering from Yonsei university, Korea.

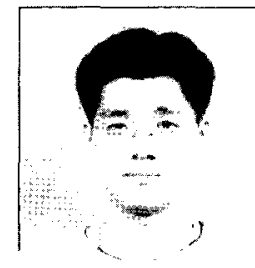

\section{Hong-Seong Kang}

He received B.S. degree in electrical Engineering from Myongji university and M.S. degree in Electrical and Electronic Engineering from Yonsei university, Korea. He is currently Ph.D candidate in Electrical and Electronic

Engineering in Yonsei university, Korea.

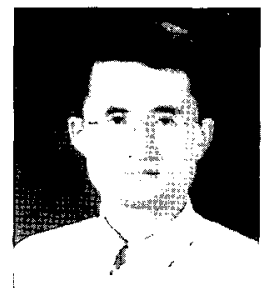

Sang-Yeol Lee

$\mathrm{He}$ received BS degree in Electrical Engineering from Yonsei university, Korea, and M.S. and Ph.D. in Electrical Engineering from State university of New York at Buffalo, N.Y, USA. $\mathrm{He}$ is a Professor in Department of Electrical and Electronic Engineering, Yonsei university, Korea. His research interests are semiconductor processing, optoelectronic device, display device, memory device, and nanoel-ectronics. 